Int. J. Dev. Biol. 63: 529-539 (2019)

https://doi.org/10.1387/ijdb.190260eb

\title{
Dictyostelium as model for studying ubiquitination and deubiquitination
}

\author{
BARBARA PERGOLIZZI ${ }^{*, 1}$, SALVATORE BOZZARO ${ }^{1}$ and ENRICO BRACCO ${ }^{*, 2}$ \\ ${ }^{1}$ Department of Clinical and Biological Sciences and ${ }^{2}$ Department of Oncology, \\ University of Torino, AOU S. Luigi, Orbassano (TO), Italy
}

\begin{abstract}
By protein quality control and degradation, the ubiquitin system drives many essential regulatory processes such as cell cycle and division, signalling, DNA replication and repair.Therefore, dysfunctions in the ubiquitin system lead to many human disease states. However, despite the immense progress made over the last couple of decades, it appears that the ubiquitin system is more complex and multi-faced than formerly expected. In addition to a rich repertoire of ubiquitin, ubiquitin conjugating and de-ubiquitylating enzymes, the social amoeba Dictyostelium discoideum genome encodes also for a wide array of ubiquitin binding domain-containing proteins, thus offering the possibility to explore the biology of the ubiquitin system from cell and molecular biology points of view. We here provide an overview on the current knowledge about the Ub-system components and we discuss how Dictyostelium might be an outstanding eukaryotic cell model for unravelling the still mostly unknown ubiquitination mechanisms of some human diseases.
\end{abstract}

KEY WORDS: Dictyostelium, human malignancies, ubiquitin system, PTM

\section{Introduction}

To handle the different extracellular cues, cells require to quickly adjust the functional status of the existing proteins. In this context, Post Translational Modifications (PTMs), achieved by the covalent linkage of different functional groups to proteins, play a crucial role. Overall, PTMs accurately specify the cellular duties of proteins by properly regulating their subcellular localization and activity. Ubiquitination (or ubiquitylation), is among the most evolutionary conserved eukaryotic PTM that in recent years has received much attention. The process involves the formation of a covalent isopeptide bond between the C-terminal Gly of the 76-amino acid protein ubiquitin (Ub) and protein substrates (Ciechanover, 2015). The most common sites of ubiquitination are Lys residues, less frequently Ub can be attached to N-terminal Met, Ser/Thr hydroxyl and to Cys thiol groups (Kravtsova-Ivantsiv and Ciechanover, 2012). Ubiquitination controls protein fate and thus significantly contribute, in conjunction with protein synthesis, to the cellular protein homeostasis (proteostasis) (Bett, 2016). The control can occur either by targeting a protein for proteolysis through the Ubiquitin Proteasome System (UPS), thus shortening its half-life, or by influencing its interactions with other proteins. The required instructions for determining the fate of the Ub-conjugates are represented by a very complex, though highly detailed, Ub-code whose biological meaning has started to be deciphered in recent years. For the correct interpretation of the Ub-code cells require "decoders" represented by an array of Ubiquitin Binding Domains (UBDs)-containing proteins (Yau and Rape, 2016). Besides the role played by the Ub-conjugates, important for cellular functions and survival is the maintenance of a free $\mathrm{Ub}$ pool and cytosolic unanchored poly-Ub chains (Park and Ryu, 2014). Unanchored poly-Ub chains are emerging as key factor in multiple cellular responses, including innate antiviral pathways and kinase activity (Rajsbaum et al., 2014; Zeng et al., 2010). Free poly Ub-chains can also activate the aggresome pathway, another mechanism that degrades unwanted proteins to overcome proteasome overwhelming or inhibition (Ouyang et al., 2012).

Ub can be conjugated directly to a target protein or to itself either through one of its seven Lysines (Lys6, Lys11, Lys27, Lys29,

Abbreviations used in this paper: DUB, deubiquitin hydrolase; PTM, post translational modification; UB, ubiquitin; UPS, ubiquitin proteasome system.

\footnotetext{
*Address correspondence to: Barbara Pergolizzi. Department of Clinical and Biological Sciences, University of Torino, AOU S. Luigi, 10043 Orbassano (TO), Italy. +39-0116705407. Fax +39-0119038639. E-mail: barbara.pergolizzi@ unito.it - (iD) https://orcid.org/0000-0003-4686-0068 or

Bracco Enrico. Department of Oncology, University of Torino, AOU S. Luigi, 10043 Orbassano (TO), Italy. Tel. +39-0116705407. Fax $+39-0119038639$.

E-mail: enrico.bracco@unito.it - (iD) https://orcid.org/0000-0003-3170-2817
}

Supplementary Material (five tables and one figure) for this paper is available at: https://doi.org/10.1387/ijdb.190260eb

Submitted: 8 June, 2019; Accepted: 8 August, 2019.

ISSN: Online 1696-3547, Print 0214-6282 
Lys33, Lys48 and Lys63) by an isopeptide bond or in the case of linear head-to-tail poly-Ub chains, through the N-terminal Met residue. In the latter case a peptide bond, between the carboxyl group of the C-terminal Ub Gly and the Met $\alpha$-amino group of another $\mathrm{Ub}$, is synthesized. Different linkages offer theoretically countless possibilities to assemble a specific type of Ub-polymer of different length. Ub-chains deriving from a single linkage type are called homotypic whereas those containing mixed linkages are referred as heterotypic. The broad spectrum of Ub-chains topology that are found within the cells is further increased by the fact that heterotypic chains can also be branched (i.e. one Ub molecule is ubiquitynated at two or more sites) (Akutsu et al., 2016). Another additional layer of $\mathrm{Ub}$ signal regulation and/or diversification is represented by PTMs affecting Ub itself, including acetylation and phosphorylation (Koyano et al., 2014; Ohtake et al., 2015) (Fig. 1).

The ubiquitination process requires the sequential activity of Ubactivating (E1), -conjugating (E2) and -ligating (E3) enzymes. The combination of E2 and E3 enzymes specify the substrate selection and dictate the chain linkage type (Wright et al., 2016). There are three types of ubiquitination: I) a single passage through an E1-E2E3 enzymatic cascade leads to a monoubiquitinated substrate (mono-ubiquitination); II) additional passages, where several single Ub are attached to the target proteins, yield multi-ubiquitinated substrate (multi-, polymono- or multimono-ubiquitination); and III) poly-ubiquitination consisting of poly-Ub chain/s ligated to the substrate. The reversibility of the process is ensured by a special class of deubiquitin hydrolase (DUB) enzymes, affecting cellular func-

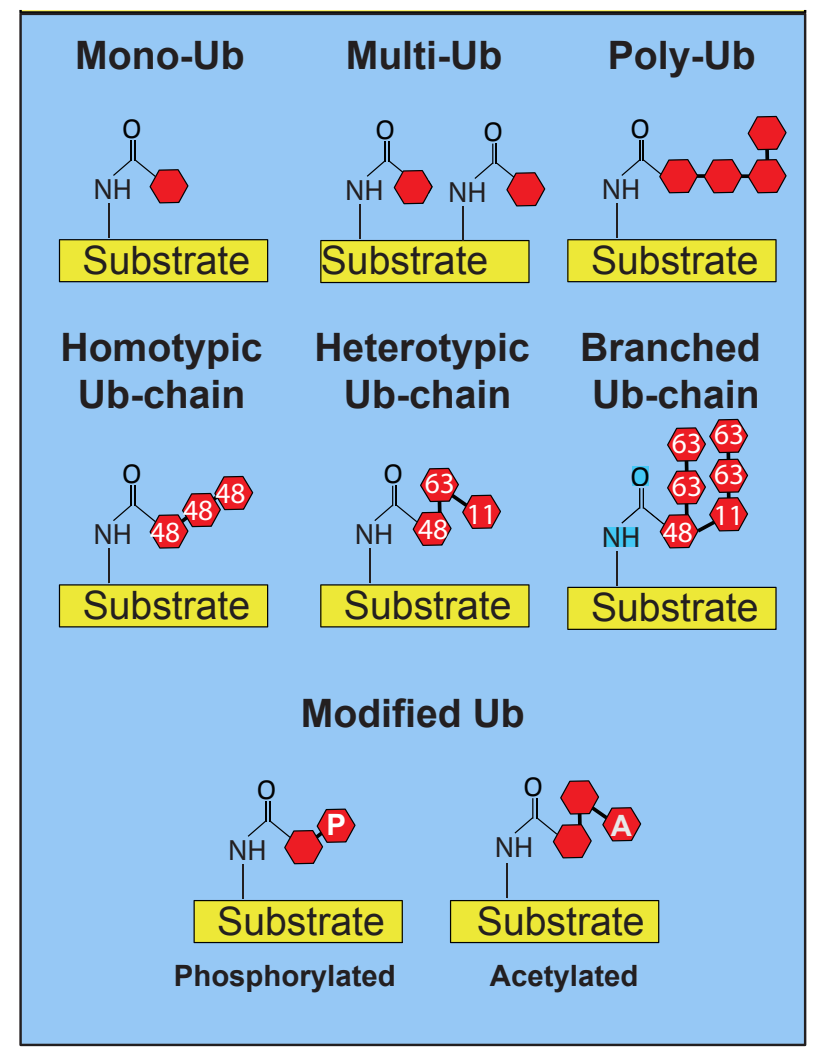

Fig. 1.The diversity of ubiquitin (Ub) signals. Protein substrates can be mono-, multi- or poly-ubiquitylated. The Ub chains can be linear (homo- or hetero-typic) and branched. Additionally, Ub molecule itself can be modified by PTMs (e.g. phosphorylation and acetylation). tion beyond simple maintenance of monomeric pools of ubiquitin.

A broad range of cellular processes, including cell-cycle and division, DNA damage recognition and repair, growth, differentiation and regulation of membrane receptors are finely regulated by Ub modifications. Therefore, it is not surprising that aberrations in the Ub-system are implicated in the pathogenesis of numerous human diseases such as cancer, central nervous system disorders, inflammation and metabolic dysfunctions (Chaugule and Walden, 2016; Popovic et al., 2014). Currently, promising emerging evidence shows that the pharmacologic manipulation of the UPS might affect the outcome of many of them, especially malignant conditions and possibly neurodegenerative and chronic inflammatory disorders (Gandolfi et al., 2017; Huang et al., 2012; Mund et al., 2014). The goal of this review is to summarize and update the role played by the Ub-system in the various aspects of Dictyostelium life cycle, and in view of the most recent findings to discuss how Dictyostelium can be exploited as potential toolkit to untangle unanswered issues.

\section{The Dictyostelium ubiquitin system repertoire}

The Dictyostelium genome harbours a quite comprehensive collection of $\mathrm{Ub}$ and $\mathrm{Ub}$ regulators encoding genes, including Ub ligases, de-ubiquitinating enzymes and Ub binding proteins, otherwise known as Ub receptors.

The Ub genes encode tandem repeats of 76-aminoacid Ub unit, constituting a multigene family of eight members in addition to four more genes containing a single Ub repeat. Two of them are fused at its 3 ' end to an unrelated extension rich in basic aminoacid residues with a remarkable similarity in the sequences to that of yeast and mammalian counterparts. In Dictyostelium the smallest of these two Ub-fusion proteins, ubex52, is a constituent of the of the ribosomes $40 \mathrm{~S}$ subunit (Muller-Taubenberger et al., 1989).

In addition to Ub, the Dictyostelium genome encodes for 10 proteins with Ub-like proteins (UBLs) (Table S1). Likewise Ub, UBLs are covalently attached to a substrate Lys residue through similar molecular mechanisms. Except for ISG15 and FAT10, all human UBLs family members, including Nedd8, UFM, URM, FAU, SUMO, Ubl5, ATG8 and ATG12 are encoded by the Dictyostelium genome. Nonetheless, differently from human, Dictyostelium genome encodes just for a single member of each UBLs, apart from ATG8, which is encoded by 2 distinct genes (TABLE S1).

As it occurs in higher eukaryotes the substrate tagging with $\mathrm{Ub}$, or UBLs, is finely tuned and requires a series of enzymatic reactions (Fig. 2).

The activation phase is characterized by the formation of a thioester bond between the C-terminal Gly residue of the $\mathrm{Ub}$ and a Cys residue present on $\mathrm{E} 1 \mathrm{Ub}$-activating enzyme requiring ATP expenditure (Burroughs et al., 2009). Structurally all E1 members so far identified are characterized by one or two THIF domains responsible for initial UBLs recognition and acyl-adenylation process.

The Dictyostelium genome harbours 12 genes encoding for putative E1 family members including two E1s for Ub. The other genes, all canonicals due to their related domain structures, are E1s for SUMO NEDD8, ATG8, ATG12, URM, FAT10 and ISG15 (Table S2). Surprisingly, though we identified the Dictyostelium orthologues E1 Ub-conjugating enzymes for FAT10 and ISG15, we didn't find their relative substrates encoding genes, suggesting that they could activate substrates other than ISG15 and FAT10. Since 


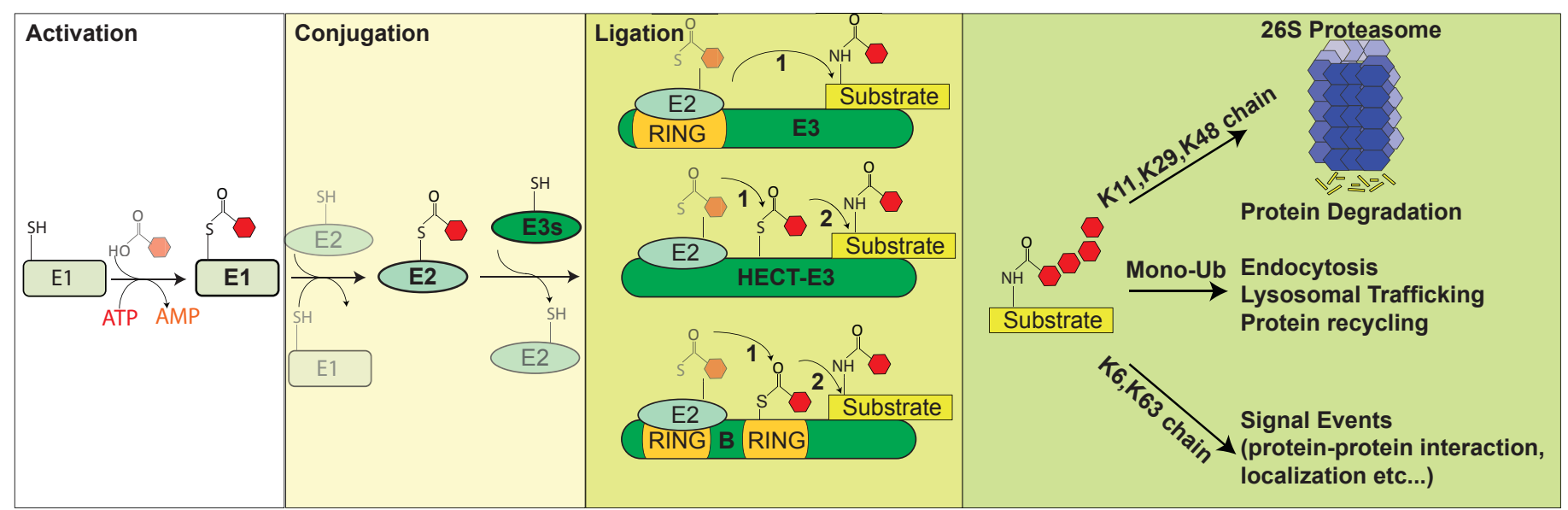

Fig. 2. The ubiquitin (Ub) system flow. Ubiquitination is a stepwise reaction: (Activation) Ub is activated in an ATP-dependent manner by E1 Ubactivating enzyme. (Conjugation) Active Ub is covalently bound to a Cys residue of an E2 Ub-conjugating enzyme. (Ligation) E3 Ub- ligases transfer the Ub and provide protein substrate specificity. Three different families of E3 ligases perform this step. Whereas RING-type E3s directly mediate the Ub transfer from the E2 Ub to the substrate, HECT members function as covalent intermediates prior Ub conjugation to the substrate. RBR ligases combine features of both RING-and HECT-type ligases. Substrates tagged with Lys 11, Lys29, Lys48-linked poly-Ub chains undergo usually proteasomal degradation, while Lys63, Lys6-linked poly-Ub and mono-Ub follow a non-proteolytic pathway.

their functional role has been mainly associated to pro-inflammatory cytokinesis it can not be excluded that these two UBLs have either appeared later, or lost, during evolution (Chen et al., 2011).

The activated $\mathrm{Ub}$ is then transferred to a Cys residue, present on the catalytic site of the E2 enzyme, through a transesterification reaction (Ciechanover, 1994). The Dictyosteliumgenome accounts for a number of E1 and E2 close to that of mammals, including human. Our previous survey (Pergolizzi et al., 2017a) estimated nearly 30 different E2s. A defining feature of all E2s is a conserved catalytic "core" domain of 150-200 amino acids (Ub-Conjugating domain, or UBC). Based on the presence, or absence of additional $\mathrm{N}$ - or C-terminal extensions, E2s are classified into 4 different families. The family I contains only the UBC domain whereas II and III have either $\mathrm{N}$ - or $\mathrm{C}$-terminal extensions, respectively. The family IV possesses both $\mathrm{N}$ - and $\mathrm{C}$-terminal expansions. These extra domains not only create E2s of diverse molecular size but can also govern intracellular localization, conferring regulatory properties and enabling specific interactions with E3s. Besides the active site, the $\mathrm{N}$-terminal surface on the UBC fold acts as scaffolds for E1 and E3 interaction. This ensures mutually exclusive interactions among E1, E2 and E3, thus regulating the ubiquitination flow (Eletr et al., 2005; Huang et al., 2005; Huang et al., 1999). All 4 E2 sub-families are encoded by Dictyostelium genome where the largest it is the type I, while only a single member (DDB_G0282783) belongs to the sub-family IV.

In ligation phase, the activated Ub is then transferred to the target protein. This step is catalysed by a large group of enzymes, with more than 600 putative members in humans and less than 150 in Dictyostelium (Pergolizzi et al., 2017a), known as E3 Ub-ligases. In conjunction with the E2s they provide substrate specificity controlling most of the cellular pathways (Nakayama and Nakayama, 2006). Based on their catalytic features and 3D structure E3 Ub-ligases are classified into three distinct families, named RING (Really Interesting New Gene), HECT (Homologous to the E6AP Carboxyl Terminus) and RBR (Ring Between Ring). As it occurs in mammals, the Dictyostelium RING sub-family possesses either monomer, dimer or multi-subunit members, but differently from mammals members of the VCB-Cul2 (Von-Hippel-Cul2/elongin) multi-subunit complex are missing (Pergolizzi et al., 2017a).

Differently from RING, HECT and RBR family members directly catalyse the Ub-transfer to the substrate through a two-step reaction: $\mathrm{Ub}$ is first transferred to a catalytic Cys residue on the E3 and then covalently linked to the substrate. HECT E3s can either function on their own or in conjunction with accessory or adaptor proteins. While the RING members' substrate selectivity and specificity requires the assembly multi-subunit complexes, for the HECT and RBR members the $\mathrm{N}$-terminal region is sufficient for substrate recognition. The Dictyostelium genome encodes 6 and 8 putative HECT and RBR family members, respectively.

Ubiquitination profoundly alters the function of proteins, affecting nearly all aspect of cellular processes. Hence, conjugation events must be tightly regulated. Beyond E3 Ub-ligases other pivotal players are deubiquitylating enzymes (DUBs), which remove Ub from target proteins. Most of DUBs catalyse a proteolytic reaction between the isopeptide bond formed between $\varepsilon$-Lys amino group of the substrate and the carboxyl group of the Ub C-terminus (Clague et al., 2013). Besides the efficient removal of the specific Ub-linkage degradation signals (degrons), that precedes the proteolysis of the Ub-conjugated proteins, DUBs are required in other cellular settings.

When compared to E3 ligase, DUBs are a relatively small group of enzymes counting nearly 95 DUBs encoding genes in the human genome (Nijman et al., 2005). They display a high degree of selectivity either for the substrates or for the diverse Ub chain types. DUBs activities can be ascribed to 4 major functional categories: I) the processing of $\mathrm{Ub}$ inactive precursors, to produce free mature monomeric Ub (Grou et al., 2015); II) the removal of monomeric Ub and poly-Ub chains from post-translationally modified proteins; III) alike some glycosidases, which can trim carbohydrate chains, DUBs might function to edit $\mathrm{Ub}$ modification from a given $\mathrm{Ub}$-conjugate by trimming poly-Ub chains thus helping to exchange one type of Ub signal for another (Lam et al., 1997) and IV) disassembling the free poly-Ub chains generated by "en bloc" removal from substrates thus ensuring that recycled $\mathrm{Ub}$ re-enter the free $\mathrm{Ub}$ pool and that 
the 26S proteasome is kept free of unanchored poly-Ub chains Swaminathan et al., 1997). DUBs are also required to maintain the Ub monomer in "good-shape". Indeed, Ub is susceptible to attack by small intracellular nucleophiles (e.g. glutathione and polyamines) thus forming non-productive Ub derivatives. In this case DUBs are essential for the salvage of adventitiously trapped Ub adducts (Pickart and Rose, 1985).

DUB family members fall into seven subfamilies, of which Ub Specific Proteases (USPs), Ub C-terminal Hydrolases (UCHs), Josephins (Machado Joseph Disease, MJD), Ovarian Tumor Proteases (OTUs), and the newly identified MINDYs and ZUP1, are Cys-dependent proteases. The seventh family, JAMM/MPN, members have metallo-isopeptidase activity. Without proper regulations, DUBs could unspecifically hydrolyze any Ub conjugate that they encounter, potentially deregulating cellular physiology. To cope with this, cells have adopted several strategies to ensure that DUB activity is channelled to the right locations at the right time. Some of these regulations occur at transcriptional level, but proteins themselves are regulated in many ways. Overall, their specificity of action is dictated by their 3D structure and by several regulation mechanisms that can be ascribed either to inter- or intra-molecular factors. Among the first there are: a) PTMs; $b$ ) sub-cellular recruitment involving dedicated factors; $c$ ) substrates that can actively assist the DUB catalysis and $d$ ) allosterical activity modulation by other proteins. Among the intramolecular layers of regulation there are: $a$ ) intramolecular activity modulators and $b$ ) target recruitment, due to peculiar domain that specifically bind target proteins (Sahtoe and Sixma, 2015). The level of specificity is not restricted to particular DUBs sub-families. Besides those that do not discriminate among chain linkages there are DUBs members that specifically recognize linkage specific chains. For instance, USPS, OTUs and JAMMs all include linkage specific members. Additionally, Ub-chain can be cleaved either from the end (exo) or within the chain (endo). Whereas exo-DUBs only need to bind to a single Ub, endo-DUBs to perform the cleavage must intercalate between two Ub molecules. Furthermore, DUBs might recognize the substrate and in a single-step amputates the Ub-chain. Alternatively, there are promiscuous DUBs that might either remove the Ub completely from substrate or leave the substrate monoubiquitinated. The mono-Ub could then be extended again in a sort of Ub-chain editing. In the case of mono-Ub proteins there are DUBs that specifically recognize their cognate protein substrate to surgically remove the mono-Ub. There are also DUBs (e.g. UCH family members) that effectively remove small disordered sequences from the $\mathrm{C}$-terminus of $\mathrm{Ub}$, such as peptide remnants after proteasomal degradation and C-terminal extension of polyUb precursors (Fig. 3).

Cellular DUBs can be found either associated, or not, with the 19S proteasome lid complex. The first group includes 3 members: PSMD14, UCHL5/UCH37 and USP14. All of them rescue the Ubchain before substrate protein degradation. PSMD14, a JAMM family member, is a constitutive proteasome lid component that removes poly-Ub chain in a single swoop (Liu and Jacobson, 2013). UCHL5/UCH37 and USP14 belong to the UCH sub-family and differently from PSMD14 they are not constitutive subunit of the proteasome. Their role consists in trimming poly-Ub chain by hydrolysing them at their distal end thus releasing mono-Ub for reutilization (Yao et al., 2006). Besides its catalytic role UCHL5 stimulates proteasome activity by regulating ATP hydrolysis and

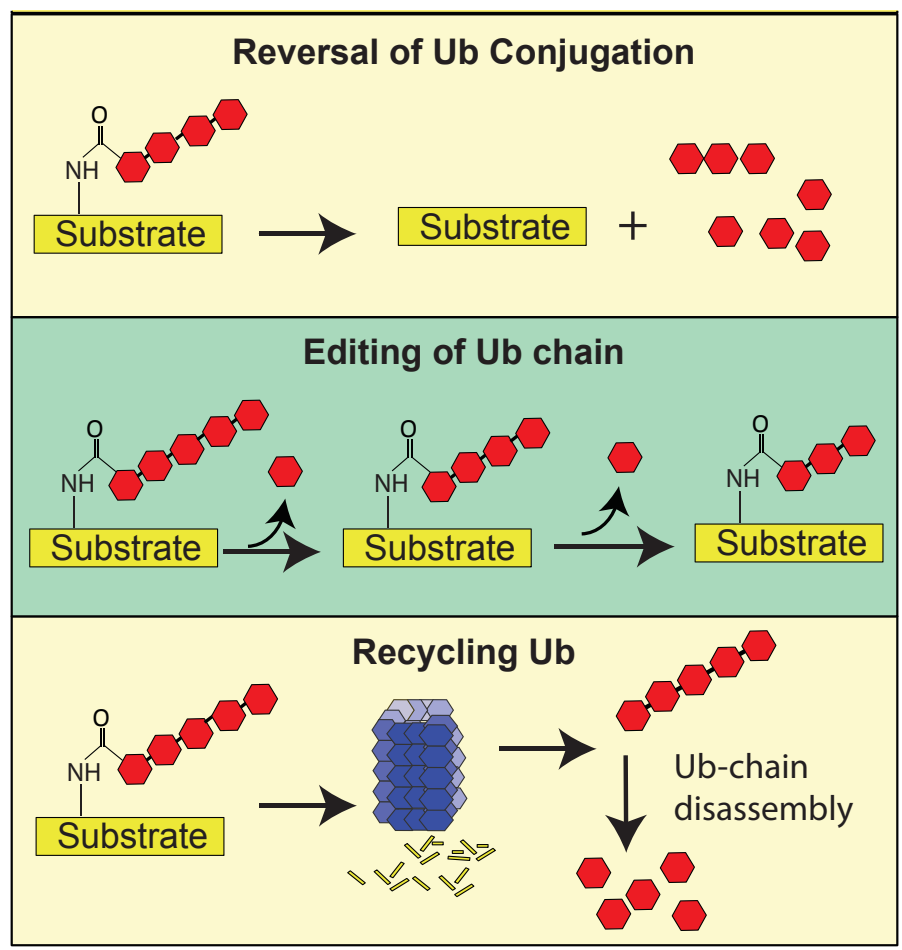

Fig. 3. Schematic representation of deubiquitin hydrolase (DUB) functions. DUBs are crucial for determining the fate of ubiquitinated proteins either by removing or by editing the length and the topology of poly-Ub chains. In addition, DUBs can also disassemble unanchored poly-Ub chains for the subsequent Ub recycling.

\section{$20 S$ gate opening.}

DUBs that function in conjunction with Ubiquitin Proteasome Pathway (UPP) include UCHL1, which is suitable for processing small Ub adducts to small peptides and thus it is proposed to function largely by maintain a stable pool of mono-Ub for use in Ubiquitination reactions, USP7/Hausp, USP9X and ataxin3 that can enhance or prevent, by trimming, proteasome degradation of Ub conjugates. Indeed, sometimes long Ub chains can impair proteasomal degradation because too long.

Other than Ub-proteasome linked role, DUBs are implied in autophagy and endosomal sorting complex (ESCRT). Several DUBs were identified as regulator of autophagy. Ub-conjugated Beclin-1 activated autophagy can be reversed by A20 (Shi and Kehrl, 2010). Furthermore, deubiquitination of mitochondrial targets by USP15, USP30 and USP35 prevented mitophagy progression (Hamacher-Brady and Brady, 2016). Capture of ubiquitylated plasma membrane proteins form endosome and their trafficking to the lysosome is mostly dependent upon the ESCRT machinery. Two DUBs, AMSH and VSP8/UBPY form a network of interaction with various ESCRT components coupling Ub-recycling with commitment to degradation in addition to proofreading functions (Wright et al., 2011).

Differently from yeasts, all mammalian DUB subfamilies are represented in the Dictyostelium proteome, including the Josephin clan, which accounts for approximately 50 different members (Table S3). As in mammalian, the larger subfamily is USP, in which the encoding genes are spread among the 6 chromosomes. Remarkably, the presence of a Josephin member places the Dictyostelium 
DUB repertoire very close to that of animal model system.

The proteins containing Ub-Binding-Domains (UBDs) assist in deciphering the signal encoded by Ub-conjugate. To date there are at least 20 different UBDs in the human genome contained within more than 100 proteins. Though, all share the capability to interact with the Ub hydrophobic patch (Leu8, Ile44, Val70) structurally they are quite divergent.

Paradigmatic is the example of the $\mathrm{SH} 3$ domains. Currently, out of approximately 300 different human $\mathrm{SH} 3$ domains only less than 5 have been shown to interact with Ub (Bezsonova et al., 2008) suggesting that the wide variety of UBDs is due to the quite disparate physico-chemical properties of the amino acids side chains surrounding the Ub hydrophobic triad. UBDs are classified in different groups according to their 3D structure: I) Ub binding surfaces are most commonly formed by alpha-helices. A single alpha helix can define a UBD, as in the case of UIM (Ub Interacting Motif), IUIM/MIU (Inverted UIM/Motif Interacting with Ub), UMI (UIM and MIU related) and DUIM (Double-sided UIM) domains. Often, Ub receptors (e.g. proteasome component S5a and ataxin-3) (Song et al., 2010; Wang et al., 2005) harbour multiple UBDs used together to increase affinity for Ub chains and to define Ub-chain linkage specificity. Flexible linker regions utilized to fit the Ub-receptors' needs usually separate the UBDs. UBDs can also gain Ub linkage specificity by oligomerization (Rahighi et al., 2009). Multiple alpha-helices can also define a UBD, as in the case of UBM (Ub Binding Motif), CUE (Coupling of Ub to Endoplasmic Reticulum), GAT (GGA And Tom), UBA (Ubiquitin Associated) and VHS (Vps/ Hrs/STAM) domains; II) the second most abundant UBD structural fold is the Zinc-Finger domain ( $\mathrm{Zn}-\mathrm{F})$, which have been shown to bind to three different regions of Ub. Some bind the Ub hydrophobic patch -e.g. UBZ (Ub-Binding Zn-F) and NZF (Npl4 -Nuclear protein localization 4- Zinc Finger) domains-, while others binds to a Ub surface centered on Asp58 (e.g. Zn-F UBD of the E3 ligase Rabex-5) (Lee et al., 2006). Eventually, the Zn-F UBP/PAZ of the DUB Isopeptidase T (IsoT/USP5) requires the recognition and interaction with the Ub's C-terminal Gly76 (Reyes-Turcu et al., 2006). Though, most of the UBDs have rather weak affinity towards Ub the latter display the strongest avidity; (II) two Pleckstrin-Homology $(\mathrm{PH})$ domains have been reported to bind to Ub, including GLUE (Gram-Like Ub-binding in Eap45) (Slagsvold et al., 2005) and PRU (Pleckstrin-like Receptor for Ub) (Schreiner et al., 2008). GLUE domain of Eap45 is a double-face domain because the same domain binds to one surface Ub whereas on the other surface binds phosphoinositides (Pls) suggesting that these two surfaces are used together to bring ubiquitinated cargo to the endosomal membrane (Alam et al., 2006). The PRU domain of the proteasome component Rpn13 by contrast does not appear to bind to PIs, but rather uses a surface opposite to its Ub-binding one to dock into the proteasome (Schreiner et al., 2008) and IV) Ub-conjugating (UBC) related domains generally contain a conserved catalytic Cys that forms a thiolester bond with Ub. All E2s interact with Ub covalently, but non-covalent surfaces have also been identified, as in the case of UbcH5 (Brzovic et al., 2006). The SH3 and WD40 beta-propellers domains represent additional UBDs (Pashkova et al., 2010; Stamenova et al., 2007).

By simply using as queries the different human UBDs and mining the Dictyostelium genome we identified a group of UBDs which, based on their aminoacid sequence similarity, is representative of almost all the human UBD types with the only exception of IUIM/MIU and DUIM (Table S4). Approximately 40 proteins containing putative alpha-helical UBD motifs have been counted, some of which such as UbpA and TOM1 have already been characterized (Blanc et al., 2009). Interestingly, TOM1 is the only Dictyostelium VHS containing protein while UbpA contains two UBDs represented by an UBA and a $\mathrm{Zn}-\mathrm{F}$ domain that, most likely, are responsible for dictating the substrate specificity. Differently from mammals, where the second largest UBD group is the Zn-F, in Dictyostelium this group is poorly represented. Since UBDs need to be experimentally validated it cannot be excluded that other $\mathrm{Zn}-\mathrm{F}$, though being distant relatives, might act as Ub receptors. Notably, our search revealed that the mammalian $\mathrm{PH}$ domain-containing proteins displaying Ub binding activity, Vps36 and Rpn13, are highly conserved in Dictyostelium as well. Finally Ub-conjugating (Ubc) related domain is a large protein group including several E2-conjugating proteins as those for NEDD8 and SUMO.

\section{Contribution of the ubiquitin system in controlling the Dictyostelium life cycle}

Dictyostelium life cycle is relatively simple, but it contains almost all of the cellular processes (movement, adhesiveness, differentiation, pattern formation, etc..) essential for the establishment of multicellular organization. Dictyosteliumamoebae divide mitotically when food is abundant but undergo multi-cellular development upon starvation. Starving cells aggregate through cAMP signal relay into groups of approximately $10^{5}$ cells. Subsequently, each cell aggregate (mound) engages in a series of well-organized movements coupled with cell differentiation to form a migrating slug, which eventually culminates to form a fruiting body consisting of a mass of spores (sorus) supported by a cellular stalk. Notably, Dictyostelium multicellularity is achieved by aggregation of preexisting cells and not by division of a precursor cell allowing the study of development in isolation from cell-cycle and -division.

Similarly to higher eukaryotes, protein degradation and signalling of Dictyostelium cells, either as solitary amoebae or as multicellular structures, are under the control of Ub system and some of the ubiquitination machinery components have already been characterized (Fig. 4).

Dictyostelium cells can either grow in axenic medium or on bacteria. In the latter case cells actively phagocytise the bacteria increasing their metabolic rate and ROS production (Dunn et al., 2017), which in turn can damage biomolecules including DNA. To preserve DNA integrity cells have evolved several mechanisms allowing the recognition and repair of damaged DNA, and the Fanconi Anemia (FA) complex is one of this (Ceccaldi et al., 2016).

In mammals thirteen genes encode for the FA core complex particularly important for DNA crosslink repair. In Dictyostelium eight out of thirteen are conserved. In this organism the FA core complex interacts with an E2 Ub-conjugating enzyme (Ube2t), to monoubiquitinate both FANCD2 and $\mathrm{FANCl}$, which in turn form a complex that colocalizes at damaged DNA sites. Defects in FANCD2 leads to a failure of the radiation-induced block of DNA replication and to sensitivity to DNA damaging agents (Zhang et al., 2009). In addition, the Dictyostelium amoebae use the DNA repair nuclease Xpf, an endonuclease associated to the FA complex, to protect their genome from mutagens released during the consumption of bacteria (Pontel et al., 2016).

The mono-ubiquitination signal plays a crucial role during plasma 


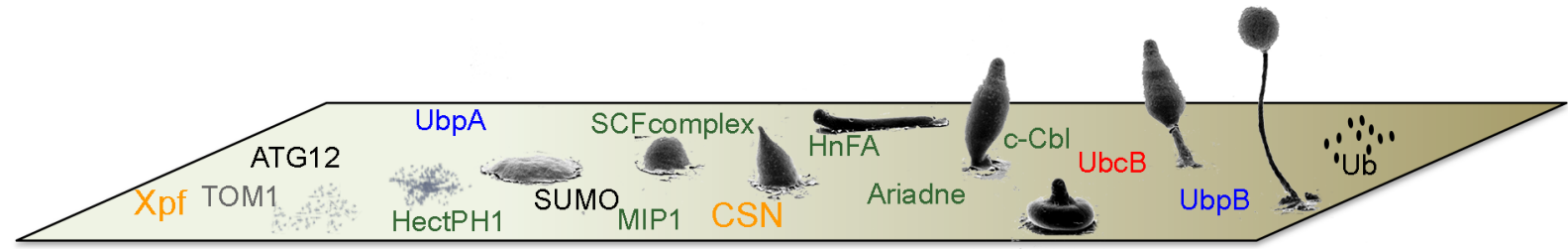

Fig. 4. Representation of the characterized ubiquitin (Ub)-system components in the life cycle of Dictyostelium. Colour code is used to distinguish the different class of Ub-system components. Red: E2; green: E3; blue: DUBs, black: Ub and UBLs; Orange: Fanconi Anemia and CSN associated components; grey: UBDs. Information regarding the whole characterized Ub-system components are available in Table S5. The relative abbreviations used in the figure are enclosed at the bottom of Table S5.

membrane proteins internalization and by sorting them into the lumen of multivesicularbodies (MVBs). In mammalian cells, the endosomal sorting requires the ESCRT-0 complex composed of VHS-containing proteins (i.e. Hrs, STAM, GGAs and Tom1). As already mentioned the Dictyostelium proteome harbours a single VHS domain containing protein (DdTOM1) that, similarly to its mammalian counterpart, interacts with Ub, clathrin, Esp15 and is capable to bind phosphatidylinositol $\mathrm{PI}(3) \mathrm{P}$ and $\mathrm{PI}(4) \mathrm{P}$. Being the only protein containing VHS domain, it has been suggested that DdTOM1could be component of an ancestral ESCRT-0 complex (Blanc et al., 2009).

Autophagy and UPS are both critical pathways for protein degradation in eukaryotic cells being both major players of proteostasis. The core autophagy protein ATG12 plays, together with ATG5 and ATG16, an essential role in the expansion of the autophagosomal membrane. In an analogous fashion to classic ubiquitination, the ubiquitin-like protein ATG12 is transferred from the E1-like enzyme ATG7 via the E2-like protein ATG10 to ATG5, and the ATG12 5 conjugate is formed. In Dictyostelium the characterization of the ATG12 and/or ATG16 null mutants has highlighted the role of these proteins in autophagy-independent process as macropinocytosis, protein homeostasis, fruiting body formation, in addition to their role in canonical autophagy (Xiong et al., 2015; Fischer et al., 2019).

Upon food exhaustion Dictyostelium cells start a growth-development transition, requiring the degradation of specific proteins. In Dictyostelium UbpA gene encodes for a DUB providing free Ub-monomers by disassembling freely cytosolic poly-Ub chains. Consistently, $U b p A$ null cells accumulate ubiquitin-containing species that co-migrate with ubiquitin polymers. Although $U b p A$ null cells are aggregation deficient, the phenotype can be partially rescued by exogenous cAMP pulses, indicating UbpA being involved in cAMP synthesis but not sensing (Lindsey et al., 1998).

Currently, the role of three members of the E3 Ub-ligase namely HectPH1, Skp1/Cul1/F-box (SCF) complex and MEK1-interacting protein (MIP1) has been assessed in the aggregation stage. $\mathrm{HectPH} 1$, a non-conventional putative member of the large mammalian HERCs, has been identified as mTORC2 suppressor (Bracco et al., 2018; Pergolizzi et al., 2017b). So far, there are no HectPH1 substrates identified, thus it has been proposed that it could act at different levels in the cAMP signalling. It could directly ubiquitinate cAR1 or proteins involved in its desensitization or alternatively components of the PKA signalling pathway, such as transcription factors (e.g. GataC) or proteins involved in mRNA maturation that regulate developmental gene expression. In addition, we have proposed that HectPH1 ubiquitinates a kinase alternative to TORC2, or a factor activating a phosphatase antagonistic to TORC2, thus regulating PKB phosphorylation (Pergolizzi et al., 2017b).
The Skp1/Cul1/F-box (SCF) complex represents a member of the multi-protein E3 Ub-ligase complex that targets specific protein substrates to UPS. FbXAregulates multicellular development interacting with CulA by targeting the intracellular phosphodiesterase RegA leading to an increase in CAMP and PKA activity (Mohanty et al., 2001; Tekinay et al., 2003). FbxA null cells fail to develop into mature fruiting body due to the paucity of pre-stalk cells, differentiating almost exclusively into spores.

In Dictyostelium cells MAP kinase cascade is required for cAMP chemotaxis, and Mitogen Extracellular Kinase (MEK1), a prototypical family member, becomes SUMOylated and ubiquitinated in response to cAMP stimulation. Both PTMs are required for its subcellular localization. Responsible for MEK1 ubiquitination is a E3-RING family member, MIP1 (Sobko et al., 2002).

The Ub-system controls also the late post-aggregative phases by a second Dictyostelium DUB member, UbpB that physically interact with the Fbox and WD40 domains of the Mitogen-activated Protein Kinase Kinase alpha (MEKK $\alpha$ ), thus controlling its stability. Very likely UbpB acts as a DUB for anchored poly-Ub chains (Clark et al., 1997).

Post-aggregative differentiation requires all E3 Ub-ligase families: RING, HECT and RBR.

Slug migration and post-aggregative cellular patterning, are regulated by three different E3 Ub-ligases, namely CbIA, HfnA, RbrA, which are member of the RING, HECT and RBR family respectively (Zheng and Shabek, 2017).

The expression of the Dictyostelium Ub-encoding genes is regulated during spore germination. In addition it is also sensitive to thermal shock, heavy metal exposure, and protein synthesis inhibition (Muller-Taubenberger et al., 1988; Kelly et al., 1983). In the past, the Dictyostelium 20S proteasome complexes have been isolated, and their proteolytic activities and cytosolic and nuclear localization were assessed (Schauer et al., 1993). More recently, a component of the 19S regulatory complex has also been characterized, displaying a range of proteasome activation broader than that of the metazoan (Masson et al., 2009).

\section{Ancient organism, new avenues}

Either the attachment of Ub to a protein substrate, or its removal, and ultimately the deciphering of the different Ub signals, contingent to the ubiquitination type (mono- $v s$ multi- $v s$ poly-ubiquitination) and Ub-chain topology, must be strictly controlled. A failure in each of these steps can lead to potentially severe consequences. Consistently, when these defects are not readily counterbalanced they contribute to the occurrence and/or progression of a variety of human diseases. In recent years, substantial progresses have 
been made in understanding the molecular basis of Ub action in malignancies-relevant processes. The E3 ligases are considered the most important players of the Ub conjugation machinery, dictating the substrate specificity. Originally Ub was identified as a "flag" to tag proteins for their subsequent proteolysis through proteasome, but it is nowadays beyond question that Ub signals govern almost every cellular process. In addition to the role played by Ub-conjugates it has emerged that monomeric Ub itself forms a cytosolic pool required for cell survival. Besides the monomeric Ub pool, cells contains also unanchored Ub-chains that have been shown to be essential for regulating diverse cellular functions ranging from virus uncoating to the regulation of kinase activity (Zeng et al., 2010). Ubiquitination reversibility is carried-out by DUBs that recognize ubiquitylated proteins and selectively remove their Ub tags.

The success of the kinase inhibitors in the last two decades has prompted the pharmaceutical industry to attempt the same strategy in targeting the Ub system. However, progress has been slow. So far, only a handful of small molecules have been successfully developed and apart the reversible proteasome inhibitor Bortezomib, fruitfully used for the treatment of multiple myeloma (Gandolfi et al., 2017), other molecules displaying such efficacy in clinic are missing. The explanation may be attributed to the lack of a well-defined catalytic pocket of most of the components of the Ub-system making them difficult to be drugged by small molecules. Moreover, many of them do not carry out a readily identifiable enzymatic function. The second reason could be ascribed to the fact that ubiquitination depends on the dynamic rearrangement of multiple protein-protein interactions that traditionally have been challenging to disrupt with small molecules. Eventually, the drug development in this field will be possible only with a detailed understanding of ubiquitination biology. Dictyostelium that has been proven to be an excellent model organism for investigating almost every cellular aspects, might represent a valuable tool for studying the cell biological processes regulated by the Ub-system. Indeed Dictyostelium offers distinct advantages that the two commonly studied yeasts do not undertake. Dictyostelium cells have a cellular biology closer to that of animals than that of yeast cells including a flexible plasma membrane rather than a rigid cell wall, the capacity to migrate towards a chemotactic source and additionally to differentiate in at least two different cell types. In addition, due to its simple and short life cycle, and to its easy of use, Dictyostelium has been commonly used to unravel the molecular mechanisms of action of drugs (e.g. lithium, cisplatin, bisphosphonate) commonly used to treat human diseases (Williams et al., 2006). Currently, this seems to be a promising future use of this organism and hopefully also as a model system for the discovery and development of new and better drugs.

FA is a rare genetic disease leading to genomic instability and increased cancer susceptibility (particularly acute myeloid leukemia). Over the years several FA mouse models have been developed, however most of them fail to spontaneously develop leukemia early in life. Yet, in most of the FA animal models bone marrow failure must be induced by challenging them with either growth factors suppressing the hematopoiesis (e.g. Interferon) or alcohol ingestion (Rosado et al., 2011). This discrepancy between animal models and humans can be explained with the lack of exposure to environmental mutagens, including food, or infections in mouse cages (Langevin et al., 2011). Furthermore, the lack of spontaneous leukemogenesis in young FA single knockout mice may be partially due to the short mice life span. Overall, these features restrict the use of animal models because they only partially recapitulate the human phenotype. In Dictyostelium cells, besides the role played in resistance to genotoxic stress (e.g. cisplatin), the FA component Xpf/ERCC4 has been shown to be crucial during the vegetative stage of life (Zhang et al., 2009). Xpfdeficient cells display normal growth rate when cultured on axenic medium but a severe growth defect is observed when cells are fed on bacteria (Pontel et al., 2016). A deeper characterization of the mutant indicated that bacterial consumption leads to mutagenic events. Alike neutrophils Dictyostelium cells kill the ingested bacteria by using respiratory burst activity that, as side effect, produces a battery of reactive molecules (e.g. reactive oxygen species/ROS), which are known to be highly mutagenic. Thus, by simply culturing Dictyostelium cells on bacteria it is possible to stimulate the genome mutational rate, mimicking what can be observed in mice only upon challenging them with either environmental- or hematopoietic-stressors. Nonetheless, even in the absence of environmental exposure to ICL-inducing agents, patients with FA display clinical symptoms at birth or early in life, thus two longstanding questions in FA research are: what is the origin and what are the natural causes of ICLs? The detailed molecular mechanisms underlying FA symptoms remain still unclear. In this respect Dictyostelium might result potentially useful to dissect the roles and regulations of the FA pathways in a less complex network. Besides the role played in DNA damage recognition and repair, FA complex plays role outside the nuclear compartment during selective autophagy process (e.g. virophagy and mitophagy) (Sumpter et al., 2016). The latter role arises an intriguingly question: why FA pathway would be involved in selective autophagy, in addition to its role in DNA damage recognition and repair? So far it has been speculated that the role played by FA components in the selective removal of mitochondria, which are the main source of endogenous ROS that in turns are responsible for DNA damage, is to minimize the generation of nuclear inter strand cross links. Unravel the FA based cross-talk between selective autophagy and DNA damage recognition and repair is a current challenge in which Dictyostelium cells might offer radically new perspectives.

Apart Ub-conjugates, free or unanchored poly-Ub chains are emerging as key determinants in multiple cellular responses. Their fate is under the control of cytosolic DUBs, such USP5/Ubp14. The Dictyostelium USP5 ortholog, UbpA, is essential for aggregation. Cells lacking UbpA fail to generate cAMP pulses being unable to activate the Adenylyl Cyclase A (ACA). Though, it has been suggested that the Dictyostelium developmental transition requires proteins degradation (Lindsey et al., 1998), a process strictly dependent upon free poly-Ub chains disassembly, the molecular mechanisms by which accumulation of cytosolic unanchored poly-Ub chains impair ACA activation remain still unknown. Yet, accumulation of free poly-Ub chains favors the formation of protein aggregates (e.g. aggresome and stress granules), which are a major contributing factor and hallmark of many neurodegenerative disorders (Wolozin, 2012). Whether, USP5 affects intracellular protein aggregates biogenesis during Dictyostelium development, remains still to be assessed. Differently from other commonly used model organisms, Dictyostelium displays high resistance to poly-Gln aggregation (Santarriaga et al., 2015) but is sensitive to unanchored poly-Ub chains accumulation. Taking advantages of these features Dictyostelium represents a unique model to eluci- 
date the poorly characterized cellular/molecular bases of poly-Ub chains-dependent but poly-GIn-independent intracellular protein aggregates. The recent coming of labelled-free non-conventional microscopy techniques, such as the implemented CARS coupled microscopy, represent fascinating and suitable tool to explore the "in vivo" dynamic of these processes (Perney et al., 2012). In the early phase of development, cAMP pulses act as chemoattractant. The cAMP sensing is provided by cAR1, a GPCR family member. Upon cAMP binding the receptor triggers various intracellular signaling events, some of which are mediated by G-protein while others (i.e. $\mathrm{Ca}^{2+}$ uptake, ERK2 and GSK3 activation) are G-protein independent. Most of the cellular responses triggered by CAMP are transient thus implying that receptors and signal transduction machinery must succeed in performing an oscillatory and regimented process of de- and re-sensitization. As it occurs in mammals upon cAMP binding, the cytoplasmic tail of receptors becomes phosphorylated, thus reducing the affinity towards the ligand. Similarly to animal cells, activated cAR1 acts as docking site for arrestin. Dictyostelium possesses several putative arrestin members accomplishing diverse functions (Cao et al., 2014). AdcB and $\mathrm{AdcC}$ regulate the frequency of $\mathrm{CAMP}$ oscillations and may link cAR1 signaling to oscillatory ERK2 activity. Arrestins have been linked to receptor down-modulation, as being actively involved in receptor mediated endocytosis. However, GPCR desensitization occurs much faster than internalization indicating that arrestins are only late players and such process is regulated by PTMs. It has recently emerged that ubiquitination is important for GPCR signaling regulation (Kennedy and Marchese, 2015). Ubiquitination of either the receptor or arrestin is required for receptor degradation and internalization, respectively. Agonist-dependent GPCR ubiquitination can occur either via direct binding of the E3 ubiquitin ligase to the receptor or indirectly through arrestin, which is acting as an adaptor bringing the E3 Ub-ligase in close proximity of the receptor. A similar mechanism might take place for cAR1 in Dictyostelium where AdcC has been found to physically interact with two E3 protein ligases, one of which belonging to the HECT family (Cao et al., 2014). The relevance of ubiquitination at GPCR level is highlighted by the fact that Dictyostelium cAR3 interacts with the CSN5/Jab subunit of COP9/signalosome complex (Rosel and Kimmel, 2006). Upon cAMP stimulation among the earliest events downstream of the G-protein there is Ras stimulation, which is immediately followed by the activation of mTORC2 and phosphatydylinositol-3 phosphate kinase (PI3K), both essential for proper chemotaxis. In Dictyostelium Protein Kinase B (PKB/Akt) as well as developmentally regulated gene expression, receptor sensitivity and PKA, but not ACA, activities are regulated by a HectPH1 which belongs to the group of large HERC proteins (Pergolizzi et al., 2017b). Though the deregulated expression and mutational status of mammals large HERCs proteins have been associated to human malignancies (ranging from neurodegenerative disorders to tumors) due to their very large size it has been very difficult to dissect their precise role. Dictyostelium may represent a novel model organism to explore the roles of the very large HERC proteins. How and to what extent such large HERC members contribute in regulating $\mathrm{PKB}$ and $\mathrm{PKA}$ activities, developmentally regulated gene expression and receptor sensitivity are future challenges. The identification of HERCs substrates and/or interacting partners will offer the opportunity to implement our current knowledge on the biology of these attractive and potentially druggable group of
E3 Ub-ligases.

Unlike mammals, Dictyostelium cells harbors a single $\mathrm{Cbl}$ orthologue - CblA- that functions, differently from animals, by downregulating a protein tyrosine phosphatase-PTP3-, responsible for STATc dephosphorylation, thus acting as a STATc positive regulator (Langenick et al., 2008). Aside STATc there are 3 additional STAT members in Dictyostelium. STATa deletion mutant displays defects in both early and late development. Though the aggregation is delayed, due to inefficient chemotaxis towards CAMP, STATa null cells form slugs, however they are defective in phototaxis (Mohanty et al., 1999). Eventually, STATa null cells remain in the slug stage occasionally forming aberrant terminal structures with a small sorus supported by undifferentiated cells. Interestingly, STATa is activated by extracellular cAMP through cAR1 in a G $\beta$ protein independent manner. Alike Dictyostelium mammalian STAT proteins can be activated via GPCRs but independently from the G-proteins (McWhinney et al., 1997). Despite mammalian GPCR make use of $\mathrm{Cbl}$ protein to transduce extracellular signals, its role has been poorly characterized, being restricted to its Ub-ligase activity and to receptor mediated endocytosis (Jacob et al., 2005). Though CblA null strain apparently shows negligible effects on cell aggregation it remains still open whether it displays any effects on STATa activity. Additional inclusive analysis of the CbIA and STATa null strains, in conjunction with a putative double mutant (Cb/A) STATa) stable cell line might shed light on several aspects of the GPCR-Cbl-STAT cross-talk that are currently still mostly shadowy.

PTMs are crucial in modulating the activity of many actin cytoskeleton regulators, including ubiquitination. Dictyostelium is an excellent model system for the analysis of the actin cytoskeleton, and research in this field has significantly contributed to a general understanding of the structure and function of cytoskeletal proteins (Noegel and Schleicher, 2000). The majority of the Dictyostelium actin cytoskeleton components are shared with animal cells. Human fascin, the Abp34 Dictyostelium ortholog, is an actin bundling protein, that facilitates the formation of filopodia thus promoting cell motility (Machesky and Li, 2010). Fascin bundling activity is under the control of Ub-system, indeed multimono-ubiquitinated fascin displays reduced and delayed bundling activity (Lin et al., 2016). Similarly, Ub mediates also human Rac1 stability and activity conferring new biochemical properties Indeed, ubiquitinated Rac1 interacts with Tollip which in turn associates with the chlatrin interacting protein Tom1 and altogether they are needed for efficient bacterial entry in CNF1 (Cytotoxic Necrotizing Factor1) intoxicated cells. Though, a Tollip encoding gene is not present in Dictyostelium genome orthologs for Rac1 and Tom 1 have been characterized. It is likely the Dictyostelium relies on alternative/ ancestral ESCRT complex/es, however this situation provides a unique model to decipher the significance of the $\mathrm{Ub}$ in controlling the Rac-Tom1 crosstalk in regulating the membrane dynamics.

\section{Conclusions and perspectives}

The biological significance of Ub-signals has revealed to be extremely complex and its comprehension requires the integration of different mechanisms, which often represents the most difficult task. Compared to animal models, Dictyostelium is less complex displaying unique advantages due to its controllability and simplicity. Every molecular tool required for genetics and cell biology has been developed for use in this system, including gene knock-outs 
and knock-ins, insertional mutagenesis, gene silencing by CRISPR/ Cas9, antisense RNAor RNAi, cell-type-specific or inducible expression system, replicative and integrative plasmids, protein tagging, organelle markers and immunostaining. With the present review, we have attempted to shed light on the extraordinary multi-faced Ub-system and its enormous physio-pathological relevance to human diseases. Even-though it is impossible to cite every aspect in which Dictyostelium might be an outstanding contributor to elucidate the deregulated Ub-dependent cellular mechanisms, in the limit of a review we have outlined how Dictyostelium can be used as model of Ub-system related human diseases.

\section{References}

AKUTSU, M., DIKIC, I. \& BREMM, A. (2016). Ubiquitin chain diversity at a glance. $J$ Cell Sci 129: 875-880.

ALAM, S. L., LANGELIER, C., WHITBY, F. G., KOIRALA, S., ROBINSON, H., HILL, C. P. \& SUNDQUIST, W. I. (2006). Structural basis for ubiquitin recognition by the human ESCRT-II EAP45 GLUE domain. Nat Struct Mol Biol 13: 1029-1030.

BETT, J. S. (2016). Proteostasis regulation by the ubiquitin system. Essays Biochem 60: 143-151.

BEZSONOVA, I., BRUCE, M. C., WIESNER, S., LIN, H., ROTIN, D. \& FORMAN-KAY, J. D. (2008). Interactions between the three CIN85 SH3 domains and ubiquitin: implications for CIN85 ubiquitination. Biochemistry 47: 8937-8949.

BLANC, C., CHARETTE, S. J., MATTEI, S., AUBRY, L., SMITH, E. W., COSSON, P. \& LETOURNEUR, F. (2009). Dictyostelium Tom1 participates to an ancestral ESCRT-0 complex. Traffic 10: 161-171.

BRACCO, E., PANUZZO, C. \& PERGOLIZZI, B. (2018). A short evolutionary journey across the HERC Ubiquitin Ligases. J. Immunol. Sci. 2: 46-49.

BRZOVIC, P. S., LISSOUNOV, A., CHRISTENSEN, D. E., HOYT, D. W. \& KLEVIT, R. E. (2006). A UbcH5/ubiquitin noncovalent complex is required for processive BRCA1-directed ubiquitination. Mol Cell 21: 873-880.

BURROUGHS, A. M., IYER, L. M. \& ARAVIND, L. (2009). Natural history of the E1-like superfamily: implication for adenylation, sulfur transfer, and ubiquitin conjugation. Proteins 75: 895-910.

CAO, X., YAN, J., SHU, S., BRZOSTOWSKI, J. A. \& JIN, T. (2014). Arrestins function in CAR1 GPCR-mediated signaling and cAR1 internalization in the development of Dictyostelium discoideum. Mol Biol Cell 25: 3210-3221.

CECCALDI, R., SARANGI, P. \& D'ANDREA, A. D. (2016). The Fanconi anaemia pathway: new players and new functions. Nat Rev Mol Cell Biol 17: 337-349.

CHAUGULE, V. K. \& WALDEN, H. (2016). Specificity and disease in the ubiquitin system. Biochem Soc Trans 44: 212-227.

CHEN, L., LI, S. \& MCGILVRAY, I. (2011). The ISG15/USP18 ubiquitin-like pathway (ISGylation system) in hepatitis $C$ virus infection and resistance to interferon therapy. Int J Biochem Cell Biol 43: 1427-1431.

CIECHANOVER, A. (1994). The ubiquitin-proteasome proteolytic pathway. Cell 79: 13: 21.

CIECHANOVER, A. (2015). The unravelling of the ubiquitin system. Nat Rev Mol Cell Biol 16: 322-324.

CLAGUE, M. J., BARSUKOV, I., COULSON, J. M., LIU, H., RIGDEN, D. J. \& URBÉ, S. (2013). Deubiquitylases from genes to organism. Physiol Rev 93: 1289-1315.

CLARK, A., NOMURA, A., MOHANTY, S. \& FIRTEL, R. A. (1997). A ubiquitinconjugating enzyme is essential for developmental transitions in Dictyostelium. Mol. Biol. Cell 8: 1989-2002.

DUNN, J. D., BOSMANI, C., BARISCH, C., RAYKOV, L., LEFRANÇOIS, L. H., CARDENAL-MUÑOZ, E., LÓPEZ-JIMÉNEZ, A. T. \& SOLDATI, T. (2017). Eat Prey, Live: As a Model for Cell-Autonomous Defenses. Front Immunol 8: 1906.

ELETR, Z. M., HUANG, D. T., DUDA, D. M., SCHULMAN, B. A. \& KUHLMAN, B. (2005). E2 conjugating enzymes must disengage from their $E 1$ enzymes before E3-dependent ubiquitin and ubiquitin-like transfer. Nat Struct Mol Biol12: 933-934.

FISCHER, S., RIJAL, R., FROMMOLT, P., WAGLE, P., KONERTZ, R., FAIX, J., MESSLIN, S. \& EICHINGER, L. (2019). Functional Characterization of UbiquitinLike Core Autophagy Protein ATG12 in. Cells 8.
GANDOLFI, S., LAUBACH, J. P., HIDESHIMA, T., CHAUHAN, D., ANDERSON, K. C. \& RICHARDSON, P. G. (2017). The proteasome and proteasome inhibitors in multiple myeloma. Cancer Metastasis Rev 36: 561-584.

GROU, C. P., PINTO, M. P., MENDES, A. V., DOMINGUES, P. \& AZEVEDO, J. E. (2015). The de novo synthesis of ubiquitin: identification of deubiquitinases acting on ubiquitin precursors. Sci Rep 5: 12836.

HAMACHER-BRADY, A. \& BRADY, N. R. (2016). Mitophagy programs: mechanisms and physiological implications of mitochondrial targeting by autophagy. Cell $\mathrm{Mol}$ Life Sci 73: 775-95.

HUANG, D. T., PAYDAR, A., ZHUANG, M., WADDELL, M. B., HOLTON, J. M. \& SCHULMAN, B. A. (2005). Structural basis for recruitment of Ubc12 by an E2 binding domain in NEDD8's E1. Mol Cell 17: 341-350.

HUANG, H.-L., WENG, H.-Y., WANG, L.-Q., YU, C.-H., HUANG, Q.-J., ZHAO, P.-P., WEN, J.-Z., ZHOU, H. \& QU, L.-H. (2012). Triggering Fbw7-mediated proteasomal degradation of c-Myc by oridonin induces cell growth inhibition and apoptosis. Mol Cancer Ther 11: 1155-1165.

HUANG, L., KINNUCAN, E., WANG, G., BEAUDENON, S., HOWLEY, P. M., HUIBREGTSE, J. M. \& PAVLETICH, N. P. (1999). Structure of an E6AP-UbcH7 complex: insights into ubiquitination by the E2-E3 enzyme cascade. Science 286: 1321-1326.

JACOB, C., COTTRELL, G. S., GEHRINGER, D., SCHMIDLIN, F., GRADY, E. F. \& BUNNETT, N. W. (2005). c-Cbl mediates ubiquitination, degradation, and downregulation of human protease-activated receptor 2. JBiol Chem280: 16076-16087.

KELLY, L. J., KELLY, R. \& ENNIS, H. L. (1983). Characterization of cDNA clones specific for sequences developmentally regulated during Dictyostelium discoideum spore germination. Mol. Cell. Biol. 3: 1943-1948.

KENNEDY, J. E. \& MARCHESE, A. (2015). Regulation of GPCR Trafficking by Ubiquitin. Biol Trans/ Sci. 132: 15: 38.

KOYANO, F., OKATSU, K., KOSAKO, H., TAMURA, Y., GO, E., KIMURA, M., KIMURA, Y., TSUCHIYA, H., YOSHIHARA, H., HIROKAWA, T., ENDO, T., FON, E. A., TREMPE, J.-F., SAEKI, Y., TANAKA, K. \& MATSUDA, N. (2014). Ubiquitin is phosphorylated by PINK1 to activate parkin. Nature 510: 162-166.

KRAVTSOVA-IVANTSIV, Y. \& CIECHANOVER, A. (2012). Non-canonical ubiquitinbased signals for proteasomal degradation. J Cell Sci 125: 539-548.

LAM, Y. A., XU, W., DEMARTINO, G. N. \& COHEN, R. E. (1997). Editing of ubiquitin conjugates by an isopeptidase in the $26 \mathrm{~S}$ proteasome. Nature 385: 737-740.

LANGENICK, J., ARAKI, T., YAMADA, Y. \& WILLIAMS, J. G. (2008). A Dictyostelium homologue of the metazoan $\mathrm{Cb}$ proteins regulates STAT signalling. $J$ Cell Sci 121: 3524-3530.

LANGEVIN, F., CROSSAN, G. P., ROSADO, I. V., ARENDS, M. J. \& PATEL, K. J. (2011). Fancd2 counteracts the toxic effects of naturally produced aldehydes in mice. Nature 475: 53-58.

LEE, S., TSAI, Y. C., MATTERA, R., SMITH, W. J., KOSTELANSKY, M. S., WEISSMAN A. M., BONIFACINO, J. S. \& HURLEY, J. H. (2006). Structural basis for ubiquitin recognition and autoubiquitination by Rabex-5. Nat Struct Mol Biol 13: 264-271.

LIN, S., LU, S., MULAJ, M., FANG, B., KEELEY, T., WAN, L., HAO, J., MUSCHOL, M., SUN, J. \& YANG, S. (2016). Monoubiquitination Inhibits the Actin Bundling Activity of Fascin. J Biol Chem 291: 27323-27333.

LINDSEY, D. F., AMERIK, A., DEERY, W. J., BISHOP, J. D., HOCHSTRASSER, M. \& GOMER, R. H. (1998). A deubiquitinating enzyme that disassembles free polyubiquitin chains is required for development but not growth in Dictyostelium. J. Biol. Chem. 273: 29178-29187.

LIU, C.-W. \& JACOBSON, A. D. (2013). Functions of the 19 S complex in proteasomal degradation. Trends Biochem Sci 38: 103-110.

MACHESKY, L. M. \& LI, A. (2010). Fascin: Invasive filopodia promoting metastasis. Commun Integr Biol 3: 263-270.

MASSON, P., LUNDIN, D., SODERBOM, F. \& YOUNG, P. (2009). Characterization of a REG/PA28 proteasome activator homolog in Dictyostelium discoideum indicates that the ubiquitin- and ATP-independent REGgamma proteasome is an ancient nuclear protease. Euk Cell 8: 844-851.

MCWHINNEY, C. D., HUNT, R. A., CONRAD, K. M., DOSTAL, D. E. \& BAKER, K. M. (1997). The type I angiotensin II receptor couples to Stat1 and Stat3 activation through Jak2 kinase in neonatal rat cardiac myocytes. $J$ Mol Cell Cardiol 29: 2513-2524.

MOHANTY, S., JERMYN, K. A., EARLY, A., KAWATA, T., AUBRY, L., CECCARELLI, A., SCHAAP, P., WILLIAMS, J. G. \& FIRTEL, R. A. (1999). Evidence that the 
Dictyostelium Dd-STATa protein is a repressor that regulates commitment to stalk cell differentiation and is also required for efficient chemotaxis. Development 126: 3391-3405.

MOHANTY, S., LEE, S., YADAVA, N., DEALY, M. J., JOHNSON, R. S. \& FIRTEL, R. A. (2001). Regulated protein degradation controls PKA function and cell-type differentiation in Dictyostelium. Genes Dev. 15: 1435-1448.

MULLER-TAUBENBERGER, A., HAGMANN, J., NOEGEL, A. \& GERISCH, G. (1988). Ubiquitin gene expression in Dictyostelium is induced by heat and cold shock, cadmium, and inhibitors of protein synthesis. J. Cell Sci. 90: 51-58.

MULLER-TAUBENBERGER, M., GRAACK, H.-R., GROHMANN, L., SCHLEICHER, M. \& GERISCH, G. (1989). An extended ubiquitin of Dictyostelium is located in the small ribosomal subunit. J. Biol. Chem. 264: 5319-5322.

MUND, T., LEWIS, M. J., MASLEN, S. \& PELHAM, H. R. (2014). Peptide and small molecule inhibitors of HECT-type ubiquitin ligases. Proc Natl Acad Sci USA 111: 16736-16741.

NAKAYAMA, K. I. \& NAKAYAMA, K. (2006). Ubiquitin ligases: cell-cycle control and cancer. Nat Rev Cancer 6: 369-381.

NIJMAN, S. M. B., LUNA-VARGAS, M. P. A., VELDS, A., BRUMMELKAMP, T. R., DIRAC, A. M. G., SIXMA, T. K. \& BERNARDS, R. (2005). Agenomic and functional inventory of deubiquitinating enzymes. Cell 123: 773-786.

NOEGEL, A. A. \& SCHLEICHER, M. (2000). The actin cytoskleleton of Dictyostelium: a story told by mutants. J. Cell Sci. 113: 759-766.

OHTAKE, F., SAEKI, Y., SAKAMOTO, K., OHTAKE, K., NISHIKAWA, H., TSUCHIYA, H., OHTA, T., TANAKA, K. \& KANNO, J. (2015). Ubiquitin acetylation inhibits polyubiquitin chain elongation. EMBO Rep 16: 192-201.

OUYANG, H., ALI, Y. O., RAVICHANDRAN, M., DONG, A., QIU, W., MACKENZIE, F., DHE-PAGANON, S., ARROWSMITH, C. H. \& ZHAI, R. G. (2012). Protein aggregates are recruited to aggresome by histone deacetylase 6 via unanchored ubiquitin C termini. J Biol Chem 287: 2317-2327.

PARK, C.-W. \& RYU, K.-Y. (2014). Cellular ubiquitin pool dynamics and homeostasis BMB Rep 47: 475-482.

PASHKOVA, N., GAKHAR, L., WINISTORFER, S. C., YU, L., RAMASWAMY, S. \& PIPER, R. C. (2010). WD40 repeat propellers define a ubiquitin-binding domain that regulates turnover of $\mathrm{F}$ box proteins. Mol Cell. 40: 433-443.

PERGOLIZZI, B., BOZZARO, S. \& BRACCO, E. (2017a). G-Protein Dependent Signal Transduction and Ubiquitination in Dictyostelium. Int J Mol Sci 18.

PERGOLIZZI, B., BRACCO, E. \& BOZZARO, S. (2017b). A new HECT ubiquitin ligase regulating chemotaxis and development in Dictyostelium discoideum. $J$ Cell Sci 130: 551-562.

PERNEY, N. M., BRADDICK, L., JURNA, M., GARBACIK, E. T., OFFERHAUS, H. L., SERPELL, L. C., BLANCH, E., HOLDEN-DYE, L., BROCKLESBY, W. S. \& MELVIN, T. (2012). Polyglutamine aggregate structure in vitro and in vivo; new avenues for coherent anti-Stokes Raman scattering microscopy. PLoS One 7: e40536.

PICKART, C. M. \& ROSE, I. A. (1985). Ubiquitin carboxyl-terminal hydrolase acts on ubiquitin carboxyl-terminal amides. J Biol Chem 260: 7903-7910.

PONTEL, L. B., LANGENICK, J., ROSADO, I. V., ZHANG, X.-Y., TRAYNOR, D., KAY, R. R. \& PATEL, K. J. (2016). Xpf suppresses the mutagenic consequences of phagocytosis in Dictyostelium. J Cell Sci 129: 4449-4454.

POPOVIC, D., VUCIC, D. \& DIKIC, I. (2014). Ubiquitination in disease pathogenesis and treatment. Nat Med 20: 1242-1253.

RAHIGHI, S., IKEDA, F., KAWASAKI, M., AKUTSU, M., SUZUKI, N., KATO, R., KENSCHE, T., UEJIMA, T., BLOOR, S., KOMANDER, D., RANDOW, F., WAKATSUKI, S. \& DIKIC, I. (2009). Specific recognition of linear ubiquitin chains by NEMO is important for NF-kappaB activation. Cell 136: 1098-1109.

RAJSBAuM, R., VERSteEG, G. A., SCHMid, S., MAESTRE, A. M., BELICHAVILLANUEVA, A., MARTÍNEZ-ROMERO, C., PATEL, J. R., MORRISON, J., PISANELLI, G., MIORIN, L., LAURENT-ROLLE, M., MOULTON, H. M., STEIN, D. A., FERNANDEZ-SESMA, A., TENOEVER, B. R. \& GARCÍA-SASTRE, A. (2014). Unanchored K48-linked polyubiquitin synthesized by the E3-ubiquitin ligase TRIM6 stimulates the interferon-IKKع kinase-mediated antiviral response. Immunity 40: 880-895.

REYES-TURCU, F. E., HORTON, J. R., MULLALLY, J. E., HEROUX, A., CHENG, X \& WILKINSON, K. D. (2006). The ubiquitin binding domain ZnF UBP recognizes the C-terminal diglycine motif of unanchored ubiquitin. Cell 124: 1197-208.

ROSADO, I. V., LANGEVIN, F., CROSSAN, G. P., TAKATA, M., PATEL, K. J. (2011) Formaldehyde catabolism is essential in cells deficient for the Fanconi anemia
DNA-repair pathway. Struct Mol Biol. 18: 1432-1434.

ROSEL, D. \& KIMMEL, A. R. (2006). The COP9 signalosome regulates cell proliferation of Dictyostelium discoideum. Eur. J. Cell Biol. 85: 1023-1034.

SAHTOE, D. D. \& SIXMA, T. K. (2015). Layers of DUB regulation. Trends Biochem Sci. 40: 456-467.

SANTARRIAGA, S., PETERSEN, A., NDUKWE, K., BRANDT, A., GERGES, N., BRUNS SCAGLIONE, J. \& SCAGLIONE, K. M. (2015). The Social Amoeba Dictyostelium discoideum Is Highly Resistant to Polyglutamine Aggregation. Biol Chem 290: 25571-25578.

SCHAUER, T. M., NESPER, M., KEHL, M., LOTTSPEICH, F., MULLER-TAUBENBERGER, A., GERISCH, G. \& BAUMEISTER, W. (1993). Proteasomes from Dictyostelium discoideum: characterization of structure and function. J. Struct Biol. 111: 135-147.

SCHREINER, P., CHEN, X., HUSNJAK, K., RANDLES, L., ZHANG, N., ELSASSER, S., FINLEY, D., DIKIC, I., WALTERS, K. J. \& GROLL, M. (2008). Ubiquitin docking at the proteasome through a novel pleckstrin-homology domain interaction. Nature 453: 548-552.

SHI, C.-S. \& KEHRL, J. H. (2010). TRAF6 and A20 regulate lysine 63-linked ubiquitination of Beclin-1 to control TLR4-induced autophagy. Sci Signal 3: ra42.

SLAGSVOLD, T., AASLAND, R., HIRANO, S., BACHE, K. G., RAIBORG, C., TRAMBAIOLO, D., WAKATSUKI, S. \& STENMARK, H. (2005). Eap45 in mammalian ESCRT-II binds ubiquitin via a phosphoinositide-interacting GLUE domain. J Biol Chem 280: 19600-19606.

SOBKO, A., MA, H. \& FIRTEL, R. A. (2002). Regulated SUMOylation and ubiquitination of DdMEK1 is required for proper chemotaxis. Dev. Cell 2: 745-756.

SONG, A.-X., ZHOU, C.-J., PENG, Y., GAO, X.-C., ZHOU, Z.-R., FU, Q.-S., HONG, J., LIN, D.-H. \& HU, H.-Y. (2010). Structural transformation of the tandem ubiquitininteracting motifs in ataxin-3 and their cooperative interactions with ubiquitin chains. PLoS One 5: e13202.

STAMENOVA, S. D., FRENCH, M. E., HE, Y., FRANCIS, S. A., KRAMER, Z. B. \& HICKE, L. (2007). Ubiquitin binds to and regulates a subset of SH3 domains. Mol Cell 25: 273-284.

SUMPTER, R., SIRASANAGANDLA, S., FERNÁNDEZ, Á. F., WEI, Y., DONG, X., FRANCO, L., ZOU, Z., MARCHAL, C., LEE, M. Y., CLAPP, D. W., HANENBERG, H. \& LEVINE, B. (2016). Fanconi Anemia Proteins Function in Mitophagy and Immunity. Cell 165: 867-881.

SWAMINATHAN, S., KRANTZ, B. A., WILKINSON, K. D. \& HOCHSTRASSER, M. (1997). In vivo disassembly of free polyubiquitin chains by yeast Ubp14 modulates rates of protein degradation by the proteasome. EMBO J 16: 4826-4838.

TEKINAY, T., ENNIS, H. L., WU, M. Y., NELSON, M., KESSIN, R. H. \& RATNER, D. I. (2003). Genetic interactions of the E3 ubiquitin ligase component FbxA with cyclic AMP metabolism and a histidine kinase signaling pathway during Dictyostelium discoideum development. Euk. Cell 2: 618-626.

WANG, Q., YOUNG, P. \& WALTERS, K. J. (2005). Structure of S5a bound to monoubiquitin provides a model for polyubiquitin recognition. J Mol Biol 348: 727-739.

WILLIAMS, R. S., BOECKELER, K., GRAF, R., MULLER-TAUBENBERGER, A., LI, Z., ISBERG, R. R., WESSELS, D., SOLL, D. R., ALEXANDER, H. \& ALEXANDER, S. (2006). Towards a molecular understanding of human diseases using Dictyostelium discoideum. Trends Mol. Med. 12: 415-424.

WOLOZIN, B. (2012). Regulated protein aggregation: stress granules and neurodegeneration. Mol Neurodegener 7: 56

WRIGHT, J. D., MACE, P. D. \& DAY, C. L. (2016). Noncovalent Ubiquitin Interactions Regulate the Catalytic Activity of Ubiquitin Writers. Trends Biochem Sci41:924-937.

WRIGHT, M. H., BERLIN, I. \& NASH, P. D. (2011). Regulation of endocytic sorting by ESCRT-DUB-mediated deubiquitination. Cell Biochem Biophys. 60: 39-46.

XIONG, Q., UNAL, C., MATTHIAS, J., STEINERT, M. \& EICHINGER, L. (2015). The phenotypes of ATG9, ATG16 and ATG9/16 knock-out mutants imply autophagydependent and -independent functions. Open Biol 5: 150008.

YAO, T., SONG, L., XU, W., DEMARTINO, G. N., FLORENS, L., SWANSON, S. K. WASHBURN, M. P., CONAWAY, R. C., CONAWAY, J. W. \& COHEN, R. E. (2006) Proteasome recruitment and activation of the Uch37 deubiquitinating enzyme by Adrm1. Nat Cell Biol 8: 994-1002.

YAU, R. \& RAPE, M. (2016). The increasing complexity of the ubiquitin code. Nat Cell Biol 27: 579-586.

ZENG, W., SUN, L., JIANG, X., CHEN, X., HOU, F., ADHIKARI, A., XU, M. \& CHEN 
Z. J. (2010). Reconstitution of the RIG-I pathway reveals a signaling role of unanchoredpolyubiquitin chains in innate immunity. Cell 142: 315-330.

ZHANG, X. Y., LANGENICK, J., TRAYNOR, D., BABU, M. M., KAY, R. R. \& PATEL, K. J. (2009). Xpf and not the Fanconi anaemia proteins or Rev3 accounts for the extreme resistance to cisplatin in Dictyostelium discoideum. PLoS Genet 5: e1000645.

ZHENG, N. and SHABEK, N. (2017). Ubiquitin Ligases: Structure, Function, and Regulation. Annu Rev Biochem 86: 129-157. 
Further Related Reading, published previously in the Int. J. Dev. Biol.

The SUMO system in Caenorhabditis elegans development

Limor Broday

Int. J. Dev. Biol. (2017) 61: 159-164

https://doi.org/10.1387/ijdb.160388LB

Dictyostelium discoideum Sir2D modulates cell-type specific gene expression and is involved in autophagy Rakhee Lohia, Punita Jain, Mukul Jain, Pradeep Kumar Burma, Anju Shrivastava and Shweta Saran

Int. J. Dev. Biol. (2017) 61: 95-104

https://doi.org/10.1387/ijdb.160038ss

Ubiquitin-mediated proteolysis in Xenopus extract

Gary S. McDowell and Anna Philpott

Int. J. Dev. Biol. (2016) 60: 263-270

https://doi.org/10.1387/ijdb.160186gm

Bimodal distribution of motility and cell fate in Dictyostelium discoideum

Pavana Goury-Sistla, Vidyanand Nanjundiah and Gopal Pande

Int. J. Dev. Biol. (2012) 56: 263-272

https://doi.org/10.1387/ijdb.113384ps

Drosophila morgue influences cell numbers and positions in the embryonic nervous system

Barbara A. Schreader, Yiqin Wang, Stephanie Carter, Joanna Grigas and John R. Nambu Int. J. Dev. Biol. (2010) 54: 1425-1433

https://doi.org/10.1387/ijdb.092979bs

Synergy between two transcription factors directs gene expression in Dictyostelium tip-organiser cells

Hong Yu Wang and Jeffrey G. Williams

Int. J. Dev. Biol. (2010) 54: 1301-1307

https://doi.org/10.1387/ijdb.103141hw

Cell-cell signaling and adhesion in phagocytosis and early development of Dictyostelium E Bracco, B Pergolizzi, B Peracino, E Ponte, A Balbo, A Mai, A Ceccarelli and S Bozzaro Int. J. Dev. Biol. (2000) 44: 733-742

http://www.intjdevbiol.com/web/paper/11061438
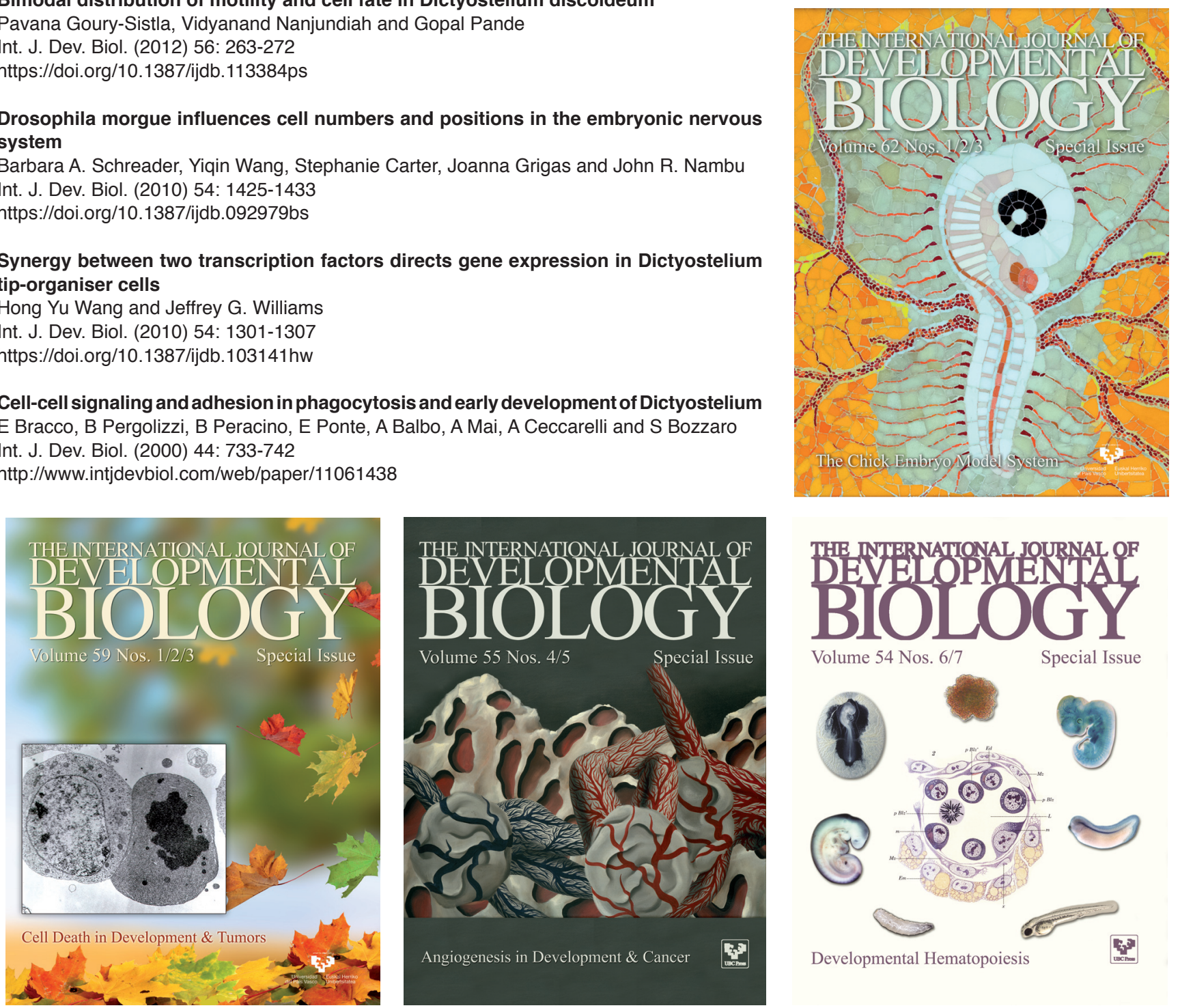

Volume 54 Nos. 6/7

Special Issue
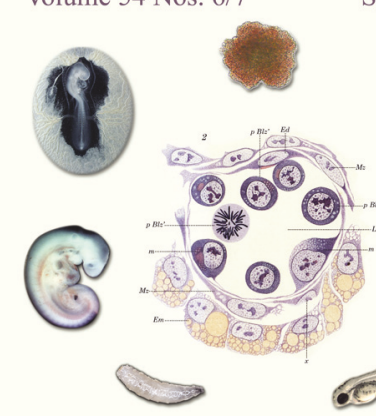

Developmental Hematopoiesis

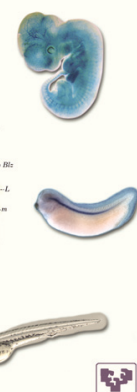

